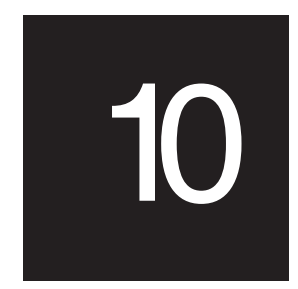

\title{
Local hierarchies of authority and development
}

\section{Kerry James}

This chapter focuses attention on an aspect of culture that is frequently overlooked in development plans. Among the most enduring of a people's cultural traits are the customary patterns of authority that are upheld within families, households, and communities. The relations of authority in these basic social units are still adhered to by most village people and entail mutual responsibilities and obligations of respect, gifts and service.

The patterns of authority at the local level may be subtle and not easily discernible to an outsider. They may alter rapidly according to material circumstances and social contexts, but this does not mean that they cannot be understood. Given sufficient time, tact, and careful investigation, it is possible to identify the most influential and authoritative people in a community or in a particular situation.

Local knowledge is not immediately available to casual observers, however, and may entirely elude developmentalists and other outsiders who most need it but visit a country only briefly. Instead of eliciting local reactions to a proposed program, the overseas consultant or development expert is more likely to spend most of a limited official visit meeting top-level bureaucrats in the nation's capital. 


\section{Participatory development}

If local-level developmental goals are to be pursued successfully, it is essential to identify the people of influence and authority, who can get things done or stifle efforts in the particular locality singled out for attention. This is especially true of programs which require a strong element of participatory development. A popular trend in recent years, participatory development is sometimes referred to as 'grassroots' development or, somewhat more inelegantly, as 'bottom-up' development.

Politically, ideologically, and practically, such programs seem a good idea because they focus on the development of human resources and small amounts of working and fixed capital such as planting materials or livestock, fish nurseries, storage depots, boats, engines, refrigerators, or whatever is needed for the particular ventures with 'the poorest of the poor'. All too frequently, however, the loftiness of the original aim equals the depth of the subsequent disillusion when the schemes are found to have gone badly wrong: when they have failed to produce the desired results or, even worse, have produced pronounced negative social and economic effects that have left the poor people markedly less well-off than they were before.

At this point, recriminations are likely to occur and, in their disappointment, people look for likely causes to blame. In retrospect, everyone is wise. All too often, culture and tradition are the easiest and most convenient whipping boys that come to hand to explain a particular failure. At the very least, these concepts are so general and so abstract that no-one in charge need feel guilty of mismanagement. Most development literature, for example, alludes to the obligations of highly traditional people to others. These obligations are generally seen to be numerous, to compete for workers' time and effort and, in the end, undermine the goals of modern development.

For all the seriousness of the charges, there is disappointingly little analysis and few case studies recording the effect of such obligations on development projects. The 'family obligations' of people living in highly traditional societies remains a diffuse and general notion, of little analytic value. As remarked above, however, the very general nature of 'culture' and the assumptions derived from it can conveniently explain the failure of development projects.

Clearly, a prerequisite of the successful implementation of 'grassroots' programs is first to find out local reactions. Instead of speaking 
generally about 'communities', it is possible to be specific and to identify precisely which people in the local community have the authority or informal influence to materially affect the progress and outcome of the developmental project, but these courses are rarely attempted.

\section{People in proximity}

People rarely engage with members of their entire extended family. Instead, they live and interact most closely with other members of their immediate household, and with members of other households to whom they are closely related who live nearby. Thus, it is the people with whom they live in close proximity, in their households and communities, who are usually the most important in terms of daily encounters, that involve activities as basic to survival as the sharing of food, productive labour, and equipment.

The relations of deference and respect, or of patron and client relations that can exist even within a family, are typically underplayed to facilitate necessary mundane cooperation and exchanges. In a small community, people's daily affairs are usually conducted with all the appearance of an easy familiarity between equals, being typically accompanied by banter, joking and laughter. The appearance of egalitarianism often belies the real situation and serves to check the personal rivalries and family feuds that can and do exist in villages. It should not be allowed to obscure the fact, however, that the relations between villagers are often delicately negotiated, handled with care and, at times, guarded zealously because it is at this level that their simple social and economic well-being or, at times of crisis, survival, most likely depends. The visiting expert's experience of people's lives at the local level, if imperfectly derived from logical deduction based on ideal statements about the culture as a whole, is generally partial, inaccurate, or non-existent.

\section{Opaque communities and oblique communications}

The sheer impenetrability of local organisation to short-term observers was brought home to me during a visit to Tonga. A team of agricultural developmentalists had made visits to two outer islands in order to gather people's reactions to proposed innovations. In particular, they wished to monitor women's reactions to the proposed changes and how the agricultural innovations might affect women or 
alter their ways of carrying out certain tasks. They had gathered together local people to discuss these matters but found that no-one would speak to them, let alone offer a frank opinion.

One of these consultants practically fell at my feet when he found I was an anthropologist: 'Thank God,' he cried, 'I have finally met someone who can explain what was going on!' During my years in the field, this reaction to my chosen profession remains unique. It is more usual for anthropologists to be greeted by developmentalists with hoots of derision or cool indifference. We are usually accused of either 'taking the people's part' in arguments over why projects failed to work, or of being fusspots who 'provide far too much detail' on issues about which the development people wish to be informed but not know too much. This is especially true of topics such as gender relations or the role of women in agriculture, which are included in their terms of reference-being, together with 'environmental issues', current aid donor buzzwords-but which do not interest, or overly concern the consultants.

In this case, however, the social scientist, namely myself, was meant to provide the key to the research dilemma immediately. 'Tell me why they wouldn't talk,' he continued desperately. 'Why, we even drew diagrams in the sand for them to illustrate the objectives of the project, but the people all sat there solemnly and would not utter a word in response.' I answered that I could not possibly say, because I had not been to those particular villages nor did I know the people who lived in them. That reply appeared to disappoint. 'But you've been in Tonga, you know the people and the culture!' Yes, to be sure, to a certain extent, I do, but not those people and not that local situation. I might have added that, by 1996, I am not sure that any people anywhere should respond to diagrams drawn for them in the sand.

To hazard a guess, however, the islanders' silence was probably because the people in question were waiting for their elders to speak first. If the elders had chosen not to speak-either because they did not understand the issues, or because they understood the issues and did not agree with the proposition but were not prepared to be so ungracious as to say so, or because they understood the issues, agreed with them and had nothing to say-or any one of a number of other possibilities; then, their junior relatives and others who were similarly inferior to them in the village structure would not speak before they did, without being asked by them to speak. 
The silence did not necessarily mean that the local community did not have ideas about the proposed scheme, but it did suggest that the consultant team did not know how to tap into that local opinion. Tonga is, after all, a highly structured society where deference is customarily shown to village and family elders, the heads of extended families, ulumotu'a, the skilled and competent people, ivilahi, and the 'keepers of the land,' tauhi fonua who are the ones who should be looked up to in a local setting. 'Oh,' sighed the expert, 'if only we had had you with us on the team!' I only smiled modestly at this novel reaction.

Although it is currently the case that more provision for 'the social components' of a project and for social researchers is being made available on consultant teams, equally, I was aware that I might not have had any more success than the team in getting the village elders to speak if they did not want to. My only advantage would have lain in knowing where the difficulty most likely was located. In such a case, it might have been more advisable to have had someone originally from the village with the team, to explain the project to the islanders. But, then, in that case, the local response probably would have depended on how the erstwhile islander was regarded in village terms, and the leaders' estimation of the person and of the family that he or she represented. If there is any lesson to be learned from the consultants' discomfiture, it is that the total social situation within which the proposed development is to take place needs to be considered as part of the initial project proposal rather than added later as an afterthought, when it has presented itself as an obstacle to the achievement of the intended goals.

\section{The total social situation}

Too often the person singled out for particular development attention, such as a training program or workshop, is assumed to be a social isolate. This is far from the case in the Pacific. Most people in Pacific island cultures, although strongly individualist, have not acceded to the notion of individualism, if what is meant is the Western idea of 'bourgeois individualism', interpreted as encouraging people to act solely in their own interests and for the promotion of their own prosperity.

Islanders see themselves as part of wider groups. Their identity derives from the sets of social relations that define them in terms of the family or wider sets of relations based on kinship and locality. These relations are the ones that they value and need. This critical difference 
between the assumptions made by both aid donors and local project directors and the lived-in realities of those they try to develop can be illustrated by the efforts in Tonga in the late 1980s to help village fishing activities.

\section{Tongan village fishing}

Reflecting upon the problems encountered in the 1980s in the implementation of their fisheries schemes, a local fisheries expert concluded that the basic flaw lay in the initial project design that had failed to take into account the wider family situation of the men who were singled out for fisheries training and given bank loans to enable them to acquire fishing boats.

The assumption of a Western-style individualism was inherent, for example, in two major aspects of the schemes. First, the skills and training that were given to village men were those that were appropriate to people wishing to set up a small business, which the village men were not prepared to do. Second, the men were given training on the assumption that they were or would become solely commercial fishermen, which was also false. These unwarranted assumptions led in some cases to the failure of the men to repay the bank loan and the loss of the boat; or, in more extreme circumstances, to the breakdown of the men's extended family life, and damage to other relationships in the village. The expert told me

Our mistake from the beginning was to overlook the family situation. The families that these trainees came from were really very wellbalanced in the way that they get food to survive as they do, though poor. The man will spend four days or so in his garden while the wife makes handicrafts. On Saturdays, he goes fishing and sells fish and uses the little cash he gets to offset the costs of bully beef for Sunday lunch, and so on.

Fisheries comes along with a training plan. The individual gets interested and after training he spends five days at sea. He does not grow and has to buy his food, if he can, from the market or his relatives. The pandanus leaves to assist the wife are missing. If he does well, he's OK. It eventually balances out and the family gets on.

But most of them we destroyed, because the boat upset the balance. The family cannot manage the loan repayments and the boat is repossessed and he comes home again to nothing. In a few cases, not many, it has happened that the relatives may not recognise him [that is, want nothing more to do with him] after the things that have happened. 
At first I could not believe the failure. We had bright guys come in to the training. We gave them a fishing lesson, explained the boat, the engine, how to manage money, and the training works well; they understand it all. Then, afterwards, they go back out to the villages with boats bought with a loan we structured from the Tonga Development Bank.

Before they joined the scheme, the men, usually in their 30s and 40s, are considered young in Tongan terms, no matter that they are married and have children of their own. They have hardly any status in the village. They just have a small fishing boat, or are hanging about and using other people's equipment for the occasional fishing trip. The family income is about $\mathrm{T} \$ 45$ a week, which then suddenly rises to T\$1,000 a week.

We give them all the training in how to catch fish and nor is there a shortage of fish. But after about 8 months, we hear from the Bank, 'Oh, Sione, we have a problem with some of the fishermen: they are not repaying their loans, slowing right down.' I replied, 'What! These guys are loading tons and tons of fish!' After about a year, I found the reasons.

(1) The status of these guys just shot right up in the community because of the income they earned. Some had even become town officers. Their wives too: some were leaders of church groups or women's groups. Even their kids, during the Christmas holidays, would be made president of the basketball team. All the things like that. When you are the leader of something in a village, you are expected to do the most, give the most funds to support it, food, the basketball...

(2) So, they became the greatest member of their family. Even though young, they were looked up to by others. This too unravelled their effort and training, and helped to cream off their income.

(3) In some cases, the father was still alive and still making decisions for the family. Thus, in the village situation, someone else was taking over the decision-making for the venture, not the one who has been trained. This was fatal for the program and also led sadly to bad relations with the father who is the senior. One village man told me, 'My interest in fishing was started by my father. I got into it because he is a master fisherman. But when I got started with Fisheries, that is the last time he ever discussed fishing matters with me. Up to now, he still won't talk to me about it. I, being younger and his son, just took it for granted that I could go ahead [with my new ideas] without him and that is probably the biggest mistake as far as the family is concerned. If it had been my uncle, I don't think there would have been any 
problem, but my father is a much harder worker and a harder man. He doesn't like anyone discussing his fishing grounds. When the subject comes up, that is the end of the story between us. We can discuss anything but not this. In Tonga, as you know, the father-son relationship is a very sensitive relationship, in any case, and this blew it. So, it is sad, but there it is.'

(4) The fishing men gave more to the church as a result of all the above changes of village status.

(5) The man still went to sea but, because so many people were asking him to lend them their kids' school fees and so on, he was defaulting on the loan repayments. In addition, other people were going out, the father, another son, a neighbour's boy, as crew or helpers or to earn money for themselves. So, he might go away for one week. But the family had already agreed to certain obligations to the community and church. His wife would say, 'While you were away, the Town Officer was asking for you because you had agreed to do something but you were not here. I think you should apologise.' So, the man would send the Town Officer a few fish to keep him happy or to help in the village meeting or whatever, which all added up. In some cases, we have ended up destroying whole families that we started out to help because the fisheries boat ended up destroying the family's balancing act. In short, we had the training program but what we should have done is to look at who the trainee is within the family and who has the big influence over this person.

We should include the wife and the church minister (faifekau) in the training, and tell the minister that after his loan repayment, the man has this amount of income left. He has a child still in secondary school, fees, food, clothes, and that we think this is the amount he can afford to give to the church. Can we ask you [the church minister] for your help? If he gives more than this amount [that he can afford], will you tell him in church that he is doing the wrong thing?

At this point the expert laughed heartily to himself at the thought that the faifekau would ever endanger church revenue by doing this, because, increasingly, his standing and prestige in the church depends on the amount of money that he can pull in. The fisheries officer, however, repeated, 'We should ask the faifekau and employ the whole family approach because Tongan villagers are not primarily commercial fishermen.'

The lesson to be drawn from this exercise is inescapable-the customary hierarchy of local authority should be acknowledged from the outset as part of the development situation. It can then consciously 
be built into the project frame as part of the social context in which development is to take place and the forces can ideally be harnessed in support of the developmental effort, rather than work against it.

As it is, local mores and patterns of authority tend to be overlooked until they emerge as major stumbling blocks to the success of the project. To say that a people's culture blocks their development makes a nonsense of both terms: culture and development. It suggests that people who progress do so without or in spite of their culture, and that the people embedded in culture get left behind. Culture and tradition may suddenly intrude in ways that materially affect outcomes when not incorporated in the development scheme, but this is due to the initial conceptualisation of the development schemes rather than immutable flaws inherent in the nature of culture, tradition, and development.

\section{Possible solutions}

First, clearly, developmentalists must find out more about the people they have designated to be key figures in the development situation. By their nature, actual social relations are not as static as ideal statements of cultural norms make them out to be, nor can they be extrapolated from these statements in any simple way. By its very nature, power is labile, ductile, fluid, and runs through the interstices of formal structures. It varies according to the material and human resources that are available at any one time, for a project to succeed. These resources may change very quickly over a relatively short period if a key figure decides to migrate, falls ill, or decides to concentrate on another activity. And the obligations of the trainee to his dependents should also be taken into account.

How might that be done? One idea is to build a database on all fisheries trainees. This approach may seem inimical to Western liberal ideas. Its intention, however, is far from sinister, and involves no more than the systematic recording, for the purpose of rapid review, of what is generally known about the household circumstances of the man who has applied for assistance. In this way, the fisheries officer can quickly get some idea of the numbers of able-bodied and skilled people who are in the household or work group, and are able to help with the project, and the number of dependents such as school children and aged parents, who cannot. 
In 1987-90, Tongan Fisheries made an effort along these lines to collect relevant information from every village family involved in the training scheme: whether parents were alive and dependent on the family, if children were still at school or capable of and interested in working on the fishing project, the family's equity in house, land, or boats; its current expenditure and labour needs, whether it had other funds it could call upon, whether the wife worked, the other economic activities that the family members engaged in, how many days were spent on each type of occupation, and so on. It is possible to use the picture of the household which was built up in this way to judge whether a proposal for future assistance put forward is feasible in the light of the total family situation, and not judge it solely on the abilities of the one who has been singled out for training.

The aim is to reach mutual agreement with the applicant on what he needs to achieve his goals, which might be different from what he originally asked for. In this context, it must be remembered that the better-educated people from the village have usually left to enter government or private sector employment. The village sector is left with the least educated, who are then expected to carry out development projects, which are perhaps only effective in about 60 per cent of cases, or 60 per cent effective in any one case, because of the limitations imposed by education and experience, and by the family and community commitments and dynamics already discussed. In any event, someone other than the applicant for a bank loan or training with some insider knowledge should assess the situation. Ideally, of course, there would be an experienced anthropologist available to answer every question!

Aid donors, however, usually hold discussions only with their incountry representatives or with local bureaucrats. The assumption appears to be that any local person will know all that is required by virtue of his/her membership in the society at large, but this is far from the case. Bureaucrats from families who have worked for two or three generations in the nation's capital may claim origin and allegiance with far-away villages of which they have very little up-todate knowledge because they rarely, if ever, visit them. Accordingly, they may give a very misleading picture of a local social situation or a sectoral activity within it. They may simply accept the aid donors' assumptions that people who fish are undeveloped fishermen, or that growers will become commercial farmers if only they are helped in 
particular ways, or go along with the donors' implementation schemes because that is the way the development projects are designed.

Instead, what is needed is a model of development that includes the realities of village life in which the development is intended to take place. When these realities are ignored at the planning stage, they are likely to emerge as problems in the fruition of projects. At this point, the development agents frequently blame extended family values as obstacles to development. This makes absolutely no sense to the people concerned because it is these sets of values that give their life meaning and upon which they depend in practical terms to survive as people and as families. After all, it is usually only for the sake of their families that they undertake progressive 'development' projects at all. If the traditional values, embodied in village and family relationships are left out of the development project calculations, modern development ceases to have a great deal of personal relevance to the subjects of development.

It is time for both developmentalists and the people they intend to help to leave aside the empty rhetoric of development and to 'get real'. Many people at the local level do not necessarily have the same development goals as their national leaders or the aid donors the leaders work with, but their aims are rarely sought or formally acknowledged, much less valued and respected. When both sides of the development equation are made clear, distorted no longer through official oversight or an over-eagerness to acquire particular forms of development aid, then both the developers and the people in whose interests the development is presumably being made will benefit. Substantial progress of a kind satisfactory to both is then more likely to take place. At present, the development process tends to involve a set of formal moves between aid donors, local bureaucrats, and locallevel recipients and agents of change, in the course of which neither the appropriate personnel nor relevant grass-roots information is sought. This process of enquiry is time-consuming, not deemed necessary, and may even prove detrimental to the project design. As one Pacific island planner remarked, 'Yes, it's true: when we do a village project successfully, we tend to congratulate ourselves on having got the economics right; when we fail, we blame the culture and custom. We just put our failure right back on the poor people themselves!' 